\title{
Professor Armand Trousseau (1801-67) and the treatment of rickets
}

\author{
Peter M Dunn
}

Armand Trousseau was born in Tours in 1801 . He was a pupil of Pierre Fidèle Bretonneau (1778-1862) in Tours before graduating in Paris in 1825. He became agrégé (qualified) in 1826 and made his early reputation on yellow fever and laryngeal phthisis. The first to undertake tracheotomy in 1831, he popularised this intervention in the treatment of croup, usually due to diphtheria; he had a $25 \%$ success rate in 200 reported cases. With Belloc he wrote a laryngeal classic in 1837 and with Pidoux a text on therapeutics (1839). He was also the first to aspirate the pleural cavity (1843) and gave the first description of haemochromatosis.

In 1839 Trousseau was appointed physician to the Hôpital Ste Antoine in Paris, later moving as physician-in-chief to the Hôtel-Dieu in 1850. He appreciated the value of bedside observation and was an outstanding clinician and teacher. $\mathrm{He}$ was also extremely popular with colleagues and students because of the keenness of his intellect, his integrity, and generosity (fig 1).

In 1861-2 he published his famous two volume text Clinique Médicale de l'Hôtel-Dieu. This great work went through many editions, the third of which (1868) was translated into English by Sir John Cormack and published by the New Sydenham Society. ${ }^{1}$ It contained many accurate descriptions of diseases, especially the common infections of childhood such as scarlet fever, measles, rubella, mumps, diphtheria, whooping cough, cholera infantum and neonatal syphilis. Trousseau realised the importance of Pasteur's work on fermentation and supported the doctrine of the specific nature of disease, as the following extract on puerperal fever and erysipelas of the newborn shows. ${ }^{1}$

\section{On puerperal infection}

"...are we not somewhat warranted to inquire, whether there does not exist in the atmosphere a morbid germ, which being deposited on the umbilical, or placental, wound, or on any surgical wound, will produce in one case phlebitis, and in another erysipelas, with or without purulent infection?... These statements are not mere hypotheses: chemical analysis and the microscope prove the existence of morbific dust in hospital wards...dressings returned from the lavatories have been found still soiled with

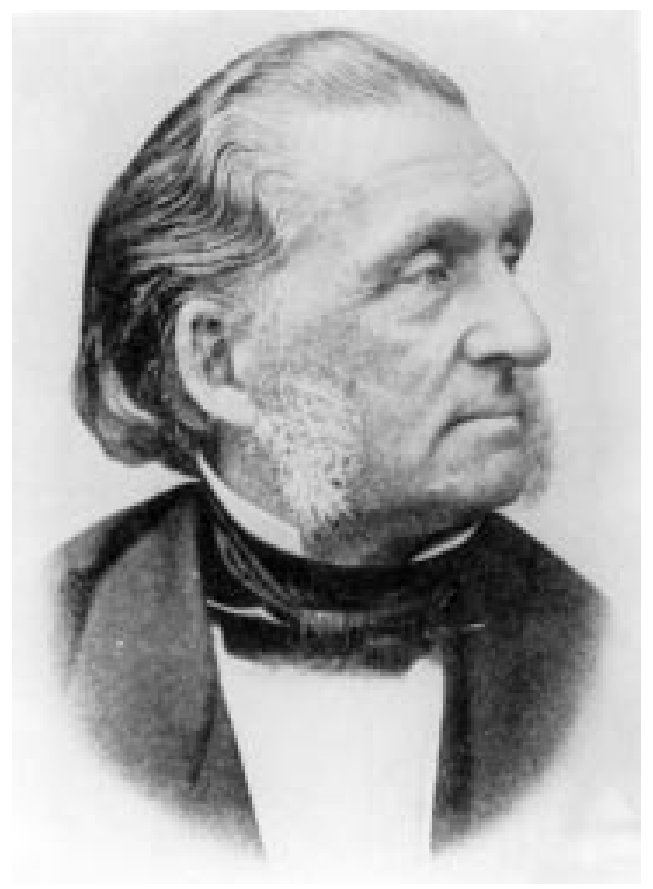

Figure 1 Professor Armand Trousseau (1801-67).

organic detritus, with linseed, and with spots, recalling the uses to which they had been formerly applied. Might not these linens, stained with blood and altered pus, be vehicles of contagion?.. There has always existed, from reasoning, a strong disposition to attribute much in the spread of endemics and epidemics, to the transport of morbific molecules; and now, the same conclusion has been arrived at from direct examination of the atmosphere... The germs which may exist in the atmosphere at a given time, under circumstances to be determined by future inquiry, will not become developed with equal facility in all patients, because persons differ exceedingly in respect of the conditions of receptivity: certain organisms, like certain soils, will not accept certain germs... I believe that hospital hygienics embrace means by which the germs of infection may be neutralised, and its progress modified, should the germs become developed... In conclusion, it is the duty of the physician, to place his patients under the most favourable 
hygienical conditions, which can be obtained...”

\section{On erysipelas of the newborn and puerperal fever}

"Erysipelas occurring during the first fifteen or twenty days of life is inevitably fatal...it is characterised by a vivid redness of skin, and a hard, shining appearance of the subjacent cellular tissue...epidemic puerperal fever presides over the pathology of (erysipelas in) new-born infants... The umbilicus and the uterus equally present an open way for the entrance of infection; so that if both mother and infant are placed under the same epidemic influence, it is not surprising that both should contract the same disease, just as happens to hospital patients with open wounds when similarly exposed."

Trousseau's text contains many other splendid descriptions - on lactation and dentition, on infantile convulsions, laryngismus stridulus and tetany including, of course, Trousseau's sign of carpal spasm following occlusion of the arterial blood supply to the lower arm. ${ }^{2}$ Best of all were his insights, 80 years ahead of his time, ${ }^{2}$ into the origin and management of rickets and osteomalacia. He argued that rickets was a disease brought about by nutritional deficiency and a sunless climate, that it was brought on by rapid growth, that osteomalacia was adult rickets, and that the disease could be treated by cod liver oil and exposure to sunlight. He based his views on the clinical observations of his teacher, Bretonneau, as well as on the experimental studies of Dr Jules Guérin (1838) on young puppies, as well as his own on young pigs.

\section{On rickets and its deformities}

"Rickets is a disease of early infancy: it generally supervenes at the apoch of dentition, that is to say, towards the end of the first year of life, or during the first six months of the second year ... when rickets is arrested in its progress after having acquired a certain intensity, the lesions which it has produced often remain and are incurable, continuing for life, so that the unfortunate sufferers retain horrible deformities ... these deformities are due to softening of the bones: so great is the softening, that when one tries to bend the limbs in their continuity, very great flexion is the result ... while the cavity of the true pelvis is contracted, the large pelvis has, on the contrary, a greater capacity ... the greater pelvis becomes spread out, and this spreading out contributes to the contraction of the lesser pelvis ..."

\section{On the aetiology of rickets}

"I now come, Gentlemen, to a great question - the etiology of rickets - a question of far greater importance than one might at first be inclined to suppose ... Climate has an undoubted influence upon the development of rickets. The disease is unquestionably much more common in damp cold countries than elsewhere ... But of the causes of this disease, insufficient aliment is the most powerful ... rickets is in great part dependant upon disorder in the function of nutrition, which is again dependant upon faulty feeding ... attentive observation convinces me that it is most common in infants weaned before dentition is sufficiently advanced, and fed on pap, vegetables, and even meat, in place of milk regimen which is better adapted to their digestive aptitudes ..."

\section{On rickets and osteomalacia}

"Ought we to consider, that there is a similarity between osteomalacia and rickets? I say we ought ... Osteomalacia supervenes at a period when the component parts of the skeleton have attained their complete development; and the rickets of children supervenes when the process of ossification is in progress ... In the genesis of osteomalacia, as well as in that of the rickets of children, we can trace the influence of bad hygienical conditions ... At puberty, that is, at the period of life nearest to the period of childhood, the disease most frequently develops itself ... After puberty, there are other circumstances which may favour the development of the disease. Thus, it is not uncommon to see women attacked with rickets after having had several children, or even, it may be, after a first confinement, the disease beginning immediately after delivery ... There exists, therefore, in pregnant women, a certain kind of rickets, of which osteomalacia may be considered as a more advanced stage ..."

\section{On the treatment and prevention of rickets}

"Gentlemen, I am also strongly led to believe, that rickets and osteomalacia are the same disease, by the fact, that both are wonderfully combated by the same medication. This medication may be considered as really heroic in the treatment of rickets: it consists in giving cod-liver oil, and, in a more general way, fish oil ... For very young infants, for those in whom the first dentition is not completed, milk, particularly the milk of a good nurse, must constitute the exclusive food. I attach so much importance to this rule, that I do not hesitate to prolong lactation beyond the usual term. By doing so, and without the use of any other means, I have seen the recovery of rachitic children ... In infants, after the first period of infancy, and in adults, the regimen ought to consist of a varied combination of animal and vegetable food, care being taken that the former predominates ...”

Unfortunately, Trousseau's remarkable account was largely forgotten by 1900 and it was not until 1919 when Mellanby and others discovered vitamin $\mathrm{D}$, that this common and disabling condition was brought under control.

Trousseau became professor of clinical medicine at the University of Paris and must be regarded as one of the greatest of French 
teachers. Many of his students achieved distinction including Dieulafoy, Da Costa, Brown-Sequard and Lasègne. $\mathrm{He}$ also did much to support and publicise the work of Duchenne and Charcot. For a time he was a Representative of the People at the National Assembly. He was also a member of the Imperial Academy of Medicine and several other European Societies. Many honours came his way, including Commander of the Legion of
Honour and Grand Officer of the Order of the Lion and the Sun of Persia. His writings were translated and published in Britain, America, Spain and Germany. He died at the age of 65 in 1867.

1 Trousseau A. Lectures on Clinical Medicine, Delivered at the Trousseau A. Lectures on Clinical Medicine, Delivered at the
Hottel-Dieu, Paris. 3rd Edn. 1868. Translated by Sir John Hôtel-Dieu, Paris. 3rd Edn. 1868. Translated by Sir
Cormack, London: New Sydenham Society, 1872 .

2 Mayer J. Armand Trousseau and the arrow of time. Nutrition Reviews 1957;15:321-3. 